\title{
ALLOYS FOR HYDROGEN STORAGE IN \\ NICKEL/HYDROGEN AND NICKEL/METAL HYDRIDE BATTERIES
}

\author{
Anaba Anani, Arnaldo Visintin, Konstantin Petrov and Supramaniam Srinivasan \\ Center for Electrochemical Systems and Hydrogen Research \\ Texas Engineering Experiment Station \\ Texas A\&M University System \\ College Station, TX 77843-3402
}

James J. Reilly and John R. Johnson

Department of Applied Science

Brookhaven National Laboratory

Upton, NY 11973

Ricardo B. Schwarz and Paul B. Desch
Center for Materials Science
Los Alamos, NM 87545

ABSTRACT

Since 1990, there has been an ongoing collaboration among the authors in the three laboratories to (1) prepare alloys of the $\mathrm{AB}_{5}$ and $\mathrm{AB}_{2}$ types, using arc-melting/annealing and mechanical alloying/annealing techniques; (2) examine their physico-chemical characteristics (morphology, composition); (3) determine the hydrogen absorption/desorption behavior (pressure-composition isotherms as a function of temperature); and (4) evaluate their performance characteristics as hydride electrodes (charge/discharge, capacity retention, cycle life, high rate capability). This review article presents the work carried out on representative $\mathrm{AB}_{5}$ and $\mathrm{AB}_{2}$ type modified alloys (by partial substitution or with small additives of other elements). The purpose of the modification was to optimize the thermodynamics and kinetics of the hydriding/dehydriding reactions and enhance the stabilities of the alloys for the desired battery applications. The results of our collaboration, to date, demonstrate that (1) alloys prepared by arcmelting/annealing and mechanical alloying/annealing techniques exhibit similar morphology, composition and hydriding/dehydriding characteristics; (2) alloys with the appropriate small amounts of substituent or additive elements: (i) retain the single phase structure, (ii) improve the hydriding/dehydriding reactions for the battery applications, and (iii) enhance the stability in the battery environment; and (3) the $\mathrm{AB}_{2}$ type alloys exhibit higher energy densities than the AB5 type alloys but the state-of-the-art, commercialized batteries are predominantly manufactured using $A B 5$ type alloys.

\section{RATIONALE FOR INVESTIGATIONS AND CRITERIA FOR ALLOY SELECTION}

The interest in alloys for hydrogen storage in nickel/hydrogen and, particularly, in nickel/metal hydride batteries is gaining momentum because of the high performance characteristics of these batteries, in respect to energy efficiency, energy density, high rate charge/discharge capability and cycle life. Previous studies at CESHR, TEESTAMUS have shown that the high rate of self-discharge in nickel/hydrogen batteries is due to the direct reduction of the nickel oxyhydroxide to nickel oxide (1-4). In these batteries, hydrogen is stored as a compressed gas and because of the high pressure of hydrogen the rate of transport to the nickel oxide electrode is quite rapid. In order to elucidate the mechanism of the self-discharge reaction and find methods for its inhibition, microcalorimetric and electrochemical techniques were used. These studies showed that the rate of self-discharge is proportional to the hydrogen pressure in the battery and the activity of nickel oxyhydroxide. Several types of potential inhibitors were incorporated in the nickel oxide electrode, during its fabrication or added to the electrolyte, to elucidate their effects on the rate of self-discharge. Though some additives such as lead, cobalt, and cadmium were found to have some effect, the rate of self-discharge could not be reduced significantly. Thus, this work showed that the only way in which the self-discharge could be reduced was by lowering the pressure of hydrogen in the pressure vessel. This is not fcasible because it would increase the weight and volume of the nickel/hydrogen battery; thus, it was thought at that timc that one approach would be to usc hydrides for hydrogen storage in nickel/hydrogen batteries. By using this 
approach, the hydrogen pressure could be considerably reduced and hence the rate of self-discharge considerably decreased. The added advantage is that hydrogen stored as hydrides requires a considerably smaller volume than hydrogen stored as compressed gas; further, there could also be a better packing and, hence, an improvement in the thermal management of this battery.

During the last five years, there has been a great incentive for developing nickel/metal hydride batteries. Use of nickel/metal hydride, rather than nickel/hydrogen batteries, can reduce the weight and thereby increase the specific energy, but the main impetus for developing nickel/metal hydride batteries is due to the impending legislations to curtail the production of nickel/cadmium batteries, because of the highly toxic nature of cadmium. The nickel/metal hydride batteries which are being developed, manufactured and commercialized, particularly in Japan, have a wide variety of applications: lap-top computers, cellular phones, video-cameras, etc. There is also great interest in developing nickel/metal hydride batteries as power sources for electric vehicles. The advantages of the nickel/metal hydride batteries are: (1) that their energy densities, in terms of weight or volume, are better than those for the nickel/cadmium battery; (2) their rate capabilities are approaching that of the nickel/cadmium batteries; and (3) the lifetimes of these batteries, which are still in the infant stage of development, are approaching at least 1,000 cycles $(5,6)$.

For the aforementioned type of applications, there has been, in recent times, great interest in two types of alloys for hydrogen storage - the $\mathrm{AB}_{5}$ type and the $\mathrm{AB}_{2}$ type alloys. Since the 1960 s, research on these hydrides has been fairly extensive at Brookhaven National Laboratory in New York (7) and Phillips Research Laboratory in Eindhoven (8). The pioneering work on the $\mathrm{AB}_{2}$ type alloys have been carried out at Energy Conversion Devices - a subsidiary of this company, Ovonics, has been formed recently and is presently heavily engaged in developing nickel/metal hydride batteries, particularly for the electric vehicle application (9). In these alloys, the A component is the one which forms the stable hydride. The B component performs several functions: (1) it could play a catalytic role in enhancing the hydriding/dehydriding characteristics; (2) it can alter the equilibrium pressures for the hydrogen absorption/desorption and raise it or lower it to the desired levels; and (3) it could also add to the stability of the alloys because some of the $A$ components could be readily oxidized. The $A B 5$ type alloys have a hexagonal structure while the $\mathrm{AB}_{2}$ type alloys have a cubic structure. Most of the alloys of both these types, which have been successfully used or are being developed, are multi-component. In the $\mathrm{AB}_{5}$ type alloy, the parent alloy is LaNi5, while in the $\mathrm{AB}_{2}$ type it is $\mathrm{TiNi}_{2}$ or $\mathrm{ZrNi}_{2}$. However, either the partial substitution by or a small addition of other elements alters the hydriding/dehydriding characteristics of these alloys, as required for gas phase hydrogen storage and for hydride electrodes. The roles of these substituents or additives could be to: (1) increase or decrease the crystal lattice constant and thereby change the equilibrium pressure for hydrogen absorption/desorption; (2) decrease the hysteresis during hydrogen absorption/desorption; (3) catalyze the hydriding/dehydriding reactions; and/or (4) improve the stability of these alloys by preventing oxide formation on one or more of the components.

Since 1990, there has been an ongoing collaboration among the authors in the three institutions to: (1) prepare alloys of the $\mathrm{AB}_{5}$ and $\mathrm{AB}_{2}$ types using arc-melting and mechanical alloying techniques; (2) examine their physicochemical characteristics - morphology, composition; (3) determine the hydrogen absorption/desorption behavior (pressure-composition isotherms as a function of temperature); and (4) evaluate their performance characteristics as hydride electrodes (charge/discharge, capacity retention, cycle life, high rate capability). This review article illustrates the results of the several types of investigations, which have been carried out on some selected $\mathrm{AB}_{5}$ and $\mathrm{AB}_{2}$ alloys (10-13). In most cases, the alloys were prepared by the arc-melting and annealing technique, but in some cases also by the mechanical alloying and annealing technique. A comparison of the physicochemical characteristics, including the hydriding/dehydriding reaction, was also made on the same alloy prepared by the two methods.

\section{PREPARATION AND PHYSICOCHEMICAL CHARACTERIZATION OF ALLOYS}

The $\mathrm{AB}_{2}$ and $\mathrm{AB}_{5}$ alloys were prepared by arc-melting of the constituent elements followed by annealing in an argon atmosphere ; for the $\mathrm{AB}_{2}$ type alloys, annealing was carried out at $800^{\circ} \mathrm{C}$ for three days and for the $\mathrm{AB}_{5}$ type alloys it was at $1000^{\circ} \mathrm{C}$ for 36 hours. The alloys were pulverized mechanically into powders about 100 mesh. The method of mechanical alloying (14) was used to prepare some selected alloys of the AB 5 type. Mechanical alloying is a high energy ball-milling process that repeatedly cold-welds and fractures powder particles. The microstucture that forms during mechanical alloying consists of laycrs of the starting matcrial; the thickness of the matcrial decreases with increase in mechanical alloying time leading to true alloy formation down to atomic levels. 
Phases formed are usually meta-stable both in structure and morphology and amorphousity (nano-crystallinity) is easily obtained by controlling the alloying time. Alloys were prepared using powder elements of puritronic quality, obtained from Johnson Mathey Company. A laboratory size Spex $8000 \mathrm{mixer} / \mathrm{mill}$ was used to mechanically alloy mixtures of the constituent elements contained in a tungsten carbide vial. Alloying was carried out in a high purity helium atmosphere glove box in powder charge batches of 5 grams each. Multiple mechanical alloying runs were combined to obtain 20 to 30 gram sample powders. In our investigations, over thirty alloys have been prepared and characterized. A representative list of the alloys, which were prepared using the arc-melting and/or mechanical alloying technique, is found in Table 1.

\section{PHYSICOCHEMICAL CHARACTERIZATION OF ALLOYS}

\section{Structural Characterization Using X-ray Diffraction Techniques}

Structure and phase identity of the alloy samples were characterized by $x$-ray diffraction utilizing a Scintag diffractometer with $\mathrm{Cu}-\mathrm{K} \alpha$-radiation. Typical $\mathrm{x}$-ray diffractograms for the alloys, prepared by arc-melting and annealing and by mechanical alloying and annealing, are shown in Figures 1 and 2. These figures also illustrate that the incorporation of small quantities of substituents and/or additives do not effect the single phase structure of the alloys. It is also worth mentioning that if the annealing treatment is not carried out on the mechanically alloyed samples, broad diffraction peaks are observed. However, sharp peaks are obtained by annealing because a nanocrystalline (amorphous) to crystalline transformation takes place. Depending on the temperature and time of annealing, the entire amorphous state can be transformed to an entirely crystallized state. The lattice constants and cell volumes for the selected alloys, as extracted from the $x$-ray data for the alloys, are tabulated in Table 1 . A striking result is that the cell volume for the $\mathrm{AB}_{2}$ type alloy is nearly twice that for the $\mathrm{AB}_{5}$ type. This is reflected in the considerably lower equilibrium pressures for hydrogen absorption/desorption for the $\mathrm{AB}_{2}$ type alloys than for the AB5 type alloys. The incorporation of substituents or additives can alter the lattice constants and cell volumes, and, hence, the equilibrium pressures for hydrogen absorption/desorption.

\section{Morphologic and Compositional Characterization Using Scanning Electron Microscopy - Energy Dispersive X-ray Analysis}

An analysis of the morphology, composition and distribution of the elements was made using SEM-EDAX techniques. A JSM Model 6400 Scanning Electron Microscope (equipped with a Noran 1-2 EDX unit) was used for the study. The SEM-EDAX studies confirm the $x$-ray diffraction studies in respect to morphology and the homogeneity of the alloys. A typical SEM photograph, which illustrates the homogeneity of the alloys, is shown in Figure 3. The compositions of these alloys were very close to that of the starting composition and the examinations, carried out at high resolution levels, revealed the homogeneity of the alloys, in respect to structure and composition.

\section{Evaluation of Alloys for Hydrogen Storage from Gas-Phase Pressure-Composition-Temperature Isotherms}

The pressure-composition-temperature isotherms for hydrogen absorption/desorption are generally measured by using a modified Sievert's type apparatus. The principles of the hydrogen absorption/desorption reaction may be represented by Figure 4 . With increase of pressure, there will be an increase in the amount of hydrogen absorption in the single-phase ( $\alpha$-phase) region. Hydrogen absorption is in the solid solution region and Sievert's Law is obeyed, i.e. the amount of hydrogen absorption is proportional to the hydrogen pressure. Once the formation of the single-phase alloy is completed, the second phase starts forming, (i.e. the $\beta$-phase) and this forms from the outer surface and migrates lowards the interior of the alloy. This is a two-phase region and for an ideal system there would be plateau pressure in the pressure-composition isotherm. Once the $\beta$-phase is completely formed, if any more hydrogen is to be introduced, this will again have to be with a significant increase of pressure. During desorption from the $\beta$-phase solid solution region, a decrease of pressure causes a decrease of the hydrogen content. The hydrogen desorption starts from the outer surface giving rise to the $\alpha$-phase formation and this case is exaculy the reverse during the absorption phenomenon (Figure 4). For an ideal case, there will be very little hysteresis in the hydrogen absorption and desorption isotherms, but in general there will be a slightly lower pressure in the two-phase region during desorption. Once the $\beta$-phase has been completely transformed into the $\alpha$-phase (the solid solution region), with decrease of pressure there will be a decrease in the hydrogen content. The ABs type of alloy generally 
exhibits a plateau pressure (P) that would be determined by the thermodynamics of the hydrogen absorption/desorption reactions. With increasing temperature, the plateau pressures will increase and the capacity for hydrogen absorption will decrease in this two phase region. Using the Vant-Hoff equation,

$$
\ln P=\frac{\Delta H}{R T}-\frac{\Delta S}{R}
$$

one could calculate the enthalpy $(\Delta H)$ for the absorption/desorption reactions as well as the entropy change $(\Delta S)$ for the reaction. The enthalpy change is generally of the order of about $10 \mathrm{kcal} / \mathrm{mole}$.

With the $\mathrm{AB}_{2}$ type alloys, plateau pressures are hardly observed, which could be due to some multi-phase alloy formation in the intermediate range. However, the pressures during which the absorption/desorption occur could be considerably below one atmosphere. For hydrogen storage this will be a disadvantage, but for the hydride electrodes, even though there is a considerable slope in the intermediate region of the pressure-composition isotherm, this is not a disadvantage, because at a sacrifice of, say, less than 40 or $50 \mathrm{mV}$, the coulombic capacity for the hydriding/dehydriding reaction corresponds close to the maximum hydrogen content (i.e., one atom of hydrogen for each atom of the metal). In the Sieveri's type experiments, one can calculate the amount of hydrogen $(\mathrm{H})$ absorbed by using the equation:

$$
(H)=\frac{2 U \Delta P}{R T}-\Sigma c \equiv \frac{2 U \Delta \tau}{R T} \varphi-\Sigma c
$$

where $R$ and $T$ have their usual meanings, $v$ is the volume of reservoir, $\varphi=0.01098$ is the slope of the pressure vs. transducer reading curve, $\Delta t$ is the change in transducer reading, and $\Sigma c$ is a correction factor accounting for hydrogen in the gaseous phase in equilibrium with the solid hydride phase.

The useful hydrogen content for hydrogen storage, say, from the gas phase, can be considered to be in the region between pressures of 0.5 and 5 atmospheres. In practice, for the $\mathrm{AB}_{5}$ type alloys, the range of hydrogen pressures to obtain the maximum capacity for hydrogen absorption could be even smaller. The degree of slant may be expressed by the equation:

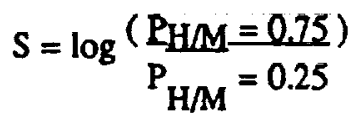

where $P_{H / M}=0.75$ and $P_{H / M}=0.25$ are the pressures at $H /$ metal ratios corresponding to 0.75 and 0.25 , respectively. An optimum hydrogen storage alloy is defined in these terms to be one with a high hydrogen capacity and a low degree of slant.

Typical hydrogen absorption/desorption isotherms for an alloy prepared at Brookhaven National Laboratory (BNL 3) are shown in Figure 5. This figure illustrates a reasonably low plateau pressure and minimum hysteresis. Further, this alloy also shows a considerable wide range over which hydrogen is absorbed and it approximately corresponds to one atom of hydrogen for each atom of metal. Table 1 summarizes the results of the hydrogen absorption/desorption characteristics of some alloys, prepared using both the arc-welding and the mechanical alloying techniques. Figure 6 shows the hydrogen absorption behavior for the alloy prepared by the mechanical alloying technique before and after annealing. Due to the amorphous nature of the alloy prior to annealing, the hydrogen absorption/desorption characteristics are not satisfactory. However, the annealing causes a transformation from the amorphous to the crystalline structure and produces grain boundaries, which are necessary for the migration of the hydrogen into the alloy; thus, the absorption/desorption characteristics are considerably improved. Figure 7 shows a comparison of the hydrogen absorption isotherms for the same alloy prepared by the mechanical alloying and by the arc-melting techniques. One can note from this figure that the characteristics are very similar, in respect to the plateau pressures; however, the alloy prepared by mechanical alloying showed a lower hydrogen content. This could, however, be improved very probably by extending the time for mechanical alloying. The incorporation of tin improves the hydrogen absorption/desorption behavior and cycle life (15). It also has some effect of lowering the plateau pressure. In addition, the substitution of neodymium increases the crystal lattice parameters and also lowers the plateau pressure ( 8 ). 


\section{EVALUATION OF ALLOYS AS HYDRIDE ELECTRODES}

\section{Charge/Discharge and Cycle Life Behavior}

Reactions which occur during the charging and discharging of hydride electrodes in alkaline electrolytes may be represented as follows:

$$
\begin{aligned}
\mathrm{M}+\mathrm{H}_{2} \mathrm{O}+\mathrm{e}^{-} & \Leftrightarrow \mathrm{M}-\mathrm{H}_{\mathrm{ads}}+\mathrm{OH}_{\text {int }}^{-} \\
\mathrm{M}-\mathrm{H}_{\text {ads }} & \Leftrightarrow \mathrm{MH} \\
\mathrm{OH}_{\text {int }}^{-} & \rightarrow \mathrm{OH}_{\text {bulk }}^{-} \\
\mathrm{MH} & \Leftrightarrow \mathrm{MH} \\
2 \mathrm{H}_{\mathrm{ads}} & \rightarrow \mathrm{H}_{2} \uparrow \\
\mathrm{M}+\mathrm{H}_{2} \mathrm{O}+\mathrm{e}^{-} & \Leftrightarrow \mathrm{MH}+\mathrm{OH}^{-}
\end{aligned}
$$

The first step (Eq. 4) is the charge transfer reaction, which gives rise to the formation of the adsorbed hydrogen and hydroxide ions at the interface. The second step (Eq. 5) involves the dissolution of $\mathrm{H}$ in the alloy and the diffusion of the absorbed hydrogen into the bulk alloy, while the hydroxide ions diffuse into the bulk of the electrolyte (Eq. 6). The third step (Eq. 7) is the recrystallization of the condensed phase. During overcharging, one could have hydrogen evolution (Eq. 8), and for practical purposes, this has to be avoided in the nickel/metal hydride batteries. The complete electrode reaction is represented by Eq. 9. The phase changes, which occur during this reaction, are identical in the gas-phase hydrogen storage. The hydride electrodes for this work were generally prepared by mixing the powder with 100 micron particle size copper powder and pressing into pellets onto nickel screens. Nickel wires were spot-welded onto the electrodes for current collection. In more recent work, instead of using copper powder, high surface area carbon with Teflon was used for the fabrication of the electrodes. The main purpose of the copper or carbon additive is to enhance the electronic conductivity of the electrode because during hydriding the electronic conductivity decreases. The Teflon serves the purpose of a binder. The typical charge/discharge behavior of the electrode, prepared with the BNL 3 material, is shown in Figure 8. This material exhibited very favorable characteristics. In terms of cycle life, a limited number of studies have been carried out to date, but one example is given in Figure 9 to show the advantages of using high surface area carbon, rather than copper, as an additive (16). Very probably, the advantage of carbon over copper is that copper could undergo some dissolution in the strong alkaline environment, whereas carbon is quite stable. There is also an enhanced capacity when using carbon as an additive. This could be connected with the very high surface area of carbon (BET surface area of about 100 or 200 $\mathrm{m}^{2} / \mathrm{g}$ ).

\section{Charge/Discharge Rate Capabilities}

For several applications, it is desirable for the hydride electrodes to be able to function at relatively high charge/discharge rates. A study was conducted on the LANL-3 material to demonstrate the performance as a function of the discharge rate (Figure 10). This figure shows that even at the $3 \mathrm{C}$ rate of charge that about $90 \%$ of the capacity could be obtained without any significant loss in the potential of the electrode. Such studies have been conducted on several of the electrodes with the other alloys listed in Table 1 and one may conclude that fast discharge rates, nearly as high as those in the nickel/cadmium battery, can be obtained with these materials. Of the materials tested to date, the one which has shown the best behavior is the BNL 4 material which is of the $\mathrm{AB}_{2}$ type.

\section{Capacity Retention}

The capacity retention is an essential criterion for secondary batteries; this parameter gives a measure of the self-discharge rate of the batteries. As mentioned in the first section, the self-discharge rate on the nickel/hydrogen batery is quite high, about $10 \%$ per day. This value is about $1 \%$ per day for the nickel/cadmium battery. Capacity retention studies were conducted by fully charging the battery and leaving it for different periods of storage time. 
After the desired periods, the remaining capacities were determined by completely discharging the batteries. Typical plots of the capacity retention and of the electrode potential, as a function of storage time, for the PRL I material are shown in Figure 11. Figure 12 shows the capacity retention as a function of storage time for several of the alloys tested in this work. An intuitive guess is that there should be a relationship between the dissolution pressure and the self-discharge rate. Table 2 demonstrates the correlation between the desorption pressures and the self-discharge rate after five days for some of the alloys. Here again, the $\mathrm{AB}_{2}$ type alloys may have some advantages over $\mathrm{AB}_{5}$ type ones because of their considerably lower plateau pressures, but as seen from Table 1, it is clear that even the $A B 5$ type alloys can be modified with substituents and/or additives to lower the plateau pressure to a level of about 0.1 to $1.0 \mathrm{~atm}$. From this article, one may conclude that hydride electrodes could function optimally with alloys having plateau pressures or even sloping pressures in the range of .1 and $.9 \mathrm{~atm}$.

\section{CONCLUSIONS}

1. Modified alloys, prepared by partial substitution of the $\bar{A}$ and $B$ components and by incorporation of minimal amounts of additives, retain the single phase structure, and provide the necessary changes in the physicochemical characteristics to attain high hydrogen storage capacities at relatively low equilibrium pressures.

2. Alloys prepared by the two methods (arc-melting/annealing and ball milling/annealing) yield very similar hydrogen absorption/desorption characteristics both in the gas phase and as hydride electrodes. The alloy preparcd by mechanical alloying attained the maximum electrochemical capacity without prior activation.

3. The $\mathrm{AB}_{5}$ type alloys, unlike the $\mathrm{AB}_{2}$ type alloys, exhibit minimal hysteresis and degree of slant of the pressure-composition isotherm for hydrogen absorption/desorption. Thus, for storage of hydrogen from the gas phase (as in $\mathrm{Ni} / \mathrm{H}_{2}$ batteries), the $\mathrm{AB}_{5}$ type alloys have a distinct advantage.

4. The $A B_{2}$ type alloys absorb/desorb hydrogen at lower pressures and have higher hydrogen storage capacities that the $\mathrm{AB}_{5}$ type alloys and hence show a higher level of performance as hydride electrodes.

5. A modified LaNi5 alloy incorporating $\mathrm{Ce}$ or $\mathrm{Nd}$ and $\mathrm{Sn}$ exhibits excellent hydrogen storage behavior from the gas phase and also as a hydride electrode.

\section{ACKNOWLEDGEMENTS}

This work was sponsored by the Office of Research and Development under contract No. 88*F674300 and the NASA Center for Space Power at Texas A\&M University (Contract P.O. 58-529211-X113). Special thanks are also due to Dr. Hong S. Lim of Hughes Aircraft Company and Mr. Joe Stockel of the U. S. Government Office of Research and Development for their encouragement and discussions of this work.

\section{REFERENCES}

1. Y.J. Kim, S. Srịnivasan and A. J. Appleby, J. Appl. Electrochemistry , 20 (1990) 377.

2. K. A. Murugesamoorthi, S. Srinivasan and A. J. Appleby, J. Appl. Electrochemistry, 21 (1991) 95.

3. Y.J. Kim, A. Visintin, S. Srinivasan and A. J. Appleby, J. Appl. Electrochemistry, 139 (1991), 351.

4. Z. Mao, A. Visintin, H. S. Lim and A. J. Appleby, J. Appl. Electrochemistry, 22, (1992) 409.

5. T. Sakai, K. Muta, H. Miyamura, N. Kuriyama, and H. Ishikawa, in D. A. Corrigan and S. Srinivasan (eds), Proceedings of the Symposium on "Hydrogen Storage Materials, Batteries and Electrochemistry", The Electrochemical Socicty, Pennington, NJ, 92-5 (1992), 59.

6. I. Matsumoto, M. Ikoma, A. Ohata, H. Matsuda and Y. Toyoguchi, Extended Abstract of 183 rd Mecting of the Electrochemical Society, The Electrochemical Socicty, Princeton, NJ, 93-1, (1993) 39. 
7. J. J. Reilly, in D. A. Corrigan and S. Srinivasan (eds) Proceedings of the Symposium on "Hydrogen Storage Materials, Batteries and Electrochemistry", The Electrochemical Society, Pennington, NJ, 92-5 (1992), 24.

8. H. H. Van Mal, K. H. J. Buschow, and A. R. Miedema, J. Less Common Metals, 35, (1974), 65.

9. M. A. Fetcenko, S. Venkatesan and S.R. Orkinsky, in D. A. Corrigan and S. Srinivasan (eds), Proceedings of the Symposium on "Hydrogen Storage Materials, Batteries and Electrochemistry", The Electrochemical Society, Pennington, NJ, 92-5 (1992), 76.

10. A. Anani, A. Visintin, S. Srinivasan and A. J. Appleby, in D. A. Corrigan and S. Srinivasan (eds), Proceedings of the Symposium on "Hydrogen Storage Materials, Batteries and Electrochemistry", The Electrochemical Society, Pennington, NJ, 92-5 (1992), 105.

11. A. Anani, A. Visintin, S. Srinivasan and A. J. Appleby, Extended Abstract of 183rd Meeting of the Electrochemical Society, The Electrochemical Society, Princeton, NJ, 93-1 (1993) 82.

12. A. Visintin, K. Petrov, S. Srinivasan A. J. Appleby J. J. Reilly, J. R. Johnson and H. S. Lim, Extended Abstract of 183rd Meeting of the Electrochemical Society. The Electrochemical Society, Princeton, NJ, 93-1, (1993) 79.

13. A. Anani, A. Visintin, S. Srinivasan, P. B. Desch and R. B. Schwarz, to be submitted to the Joumal of the Electrochemical Society.

14. R. B. Schwarz, R. R. Petrich and C. K. Saw, J. Non-Crystalline Solids, 76, (1985) 281.

15. D. Chandra and F. E. Lynch, Rare Earths, Extraction, Preparation and Applications, ed. R. G. Bautista and M. M. Wonf. The Minerals, Metals and Materials Society, (1989), 83-89.

16. K. Petrov, A. Visintin, S. Srinivasan and A. J. Appleby, Extended Abstract of 183rd Meeting of the Electrochemical Society, The Electrochemical Society, Princeton, NJ (1993) 41. 
TABLE 1

Crystallographic Parameters, Hydrogen Storage Characteristics and Coulomhic Capacities of Electrodes for Some Selected $A_{5}$ and $A_{2}$ Alloys

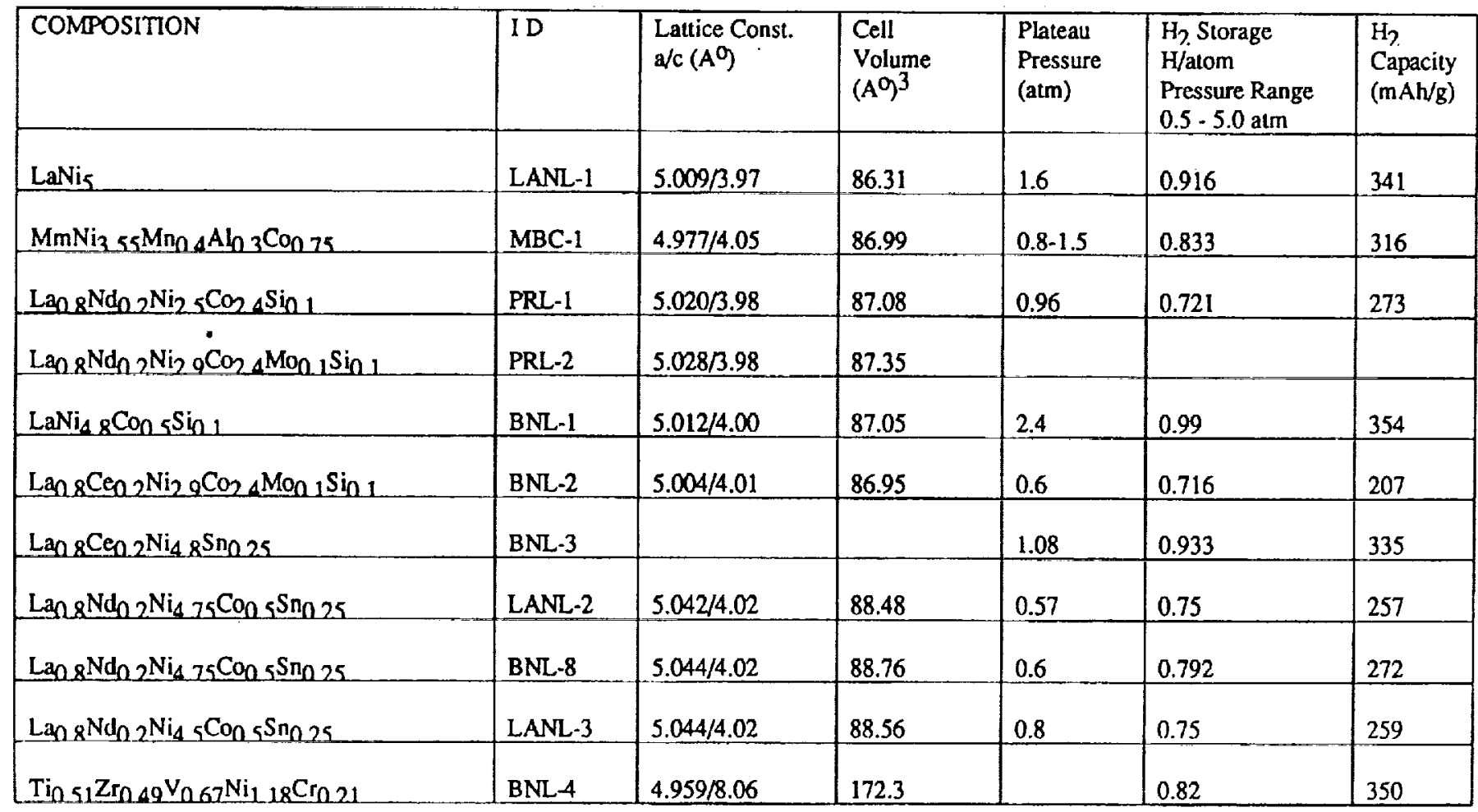

Table 2

Relationship between Desorption Pressures and Self-Discharge

for PRL-1, BNL-1, 2, and 3 Alloys

\begin{tabular}{|c|c|c|}
\hline Alloy Identification & $\begin{array}{c}\text { Desorption pressure } \\
\text { (atm) }\end{array}$ & $\begin{array}{c}\text { Self-Discharge } \\
\text { after 5 days } \\
(\%)\end{array}$ \\
\hline BNL-2 & 0.61 & 10 \\
\hline BNL-3 & 0.96 & 12 \\
\hline PRL-1 & 0.96 & 15 \\
\hline BNL-1 & 2.44 & 40 \\
\hline
\end{tabular}




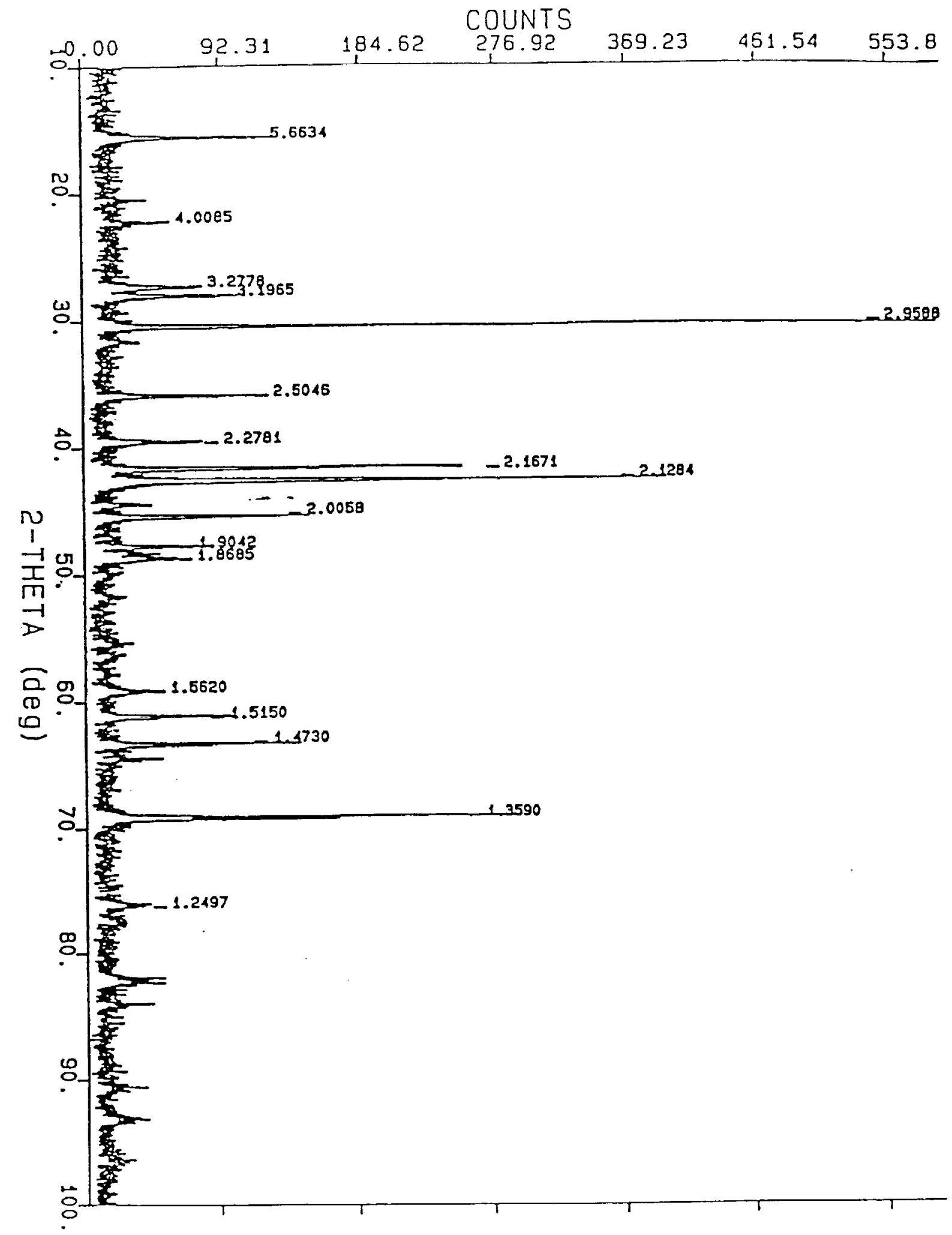

Figure 1.-X-ray diffraction pattern for BNL-1 alloy, prepared by arc-melting and annealing. Numbers above peaks represent $d$-spacing in $A^{0}$. 


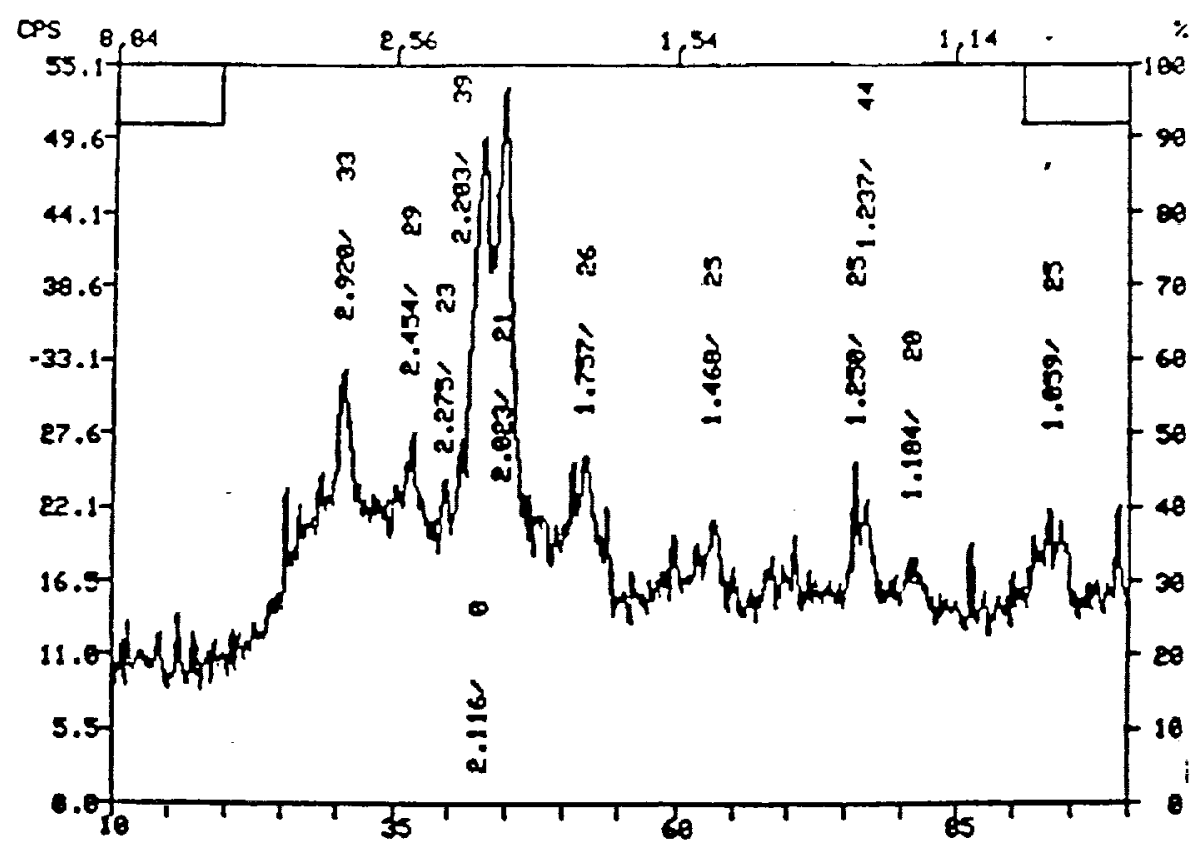

(a) Prepared by mechanical alloying.

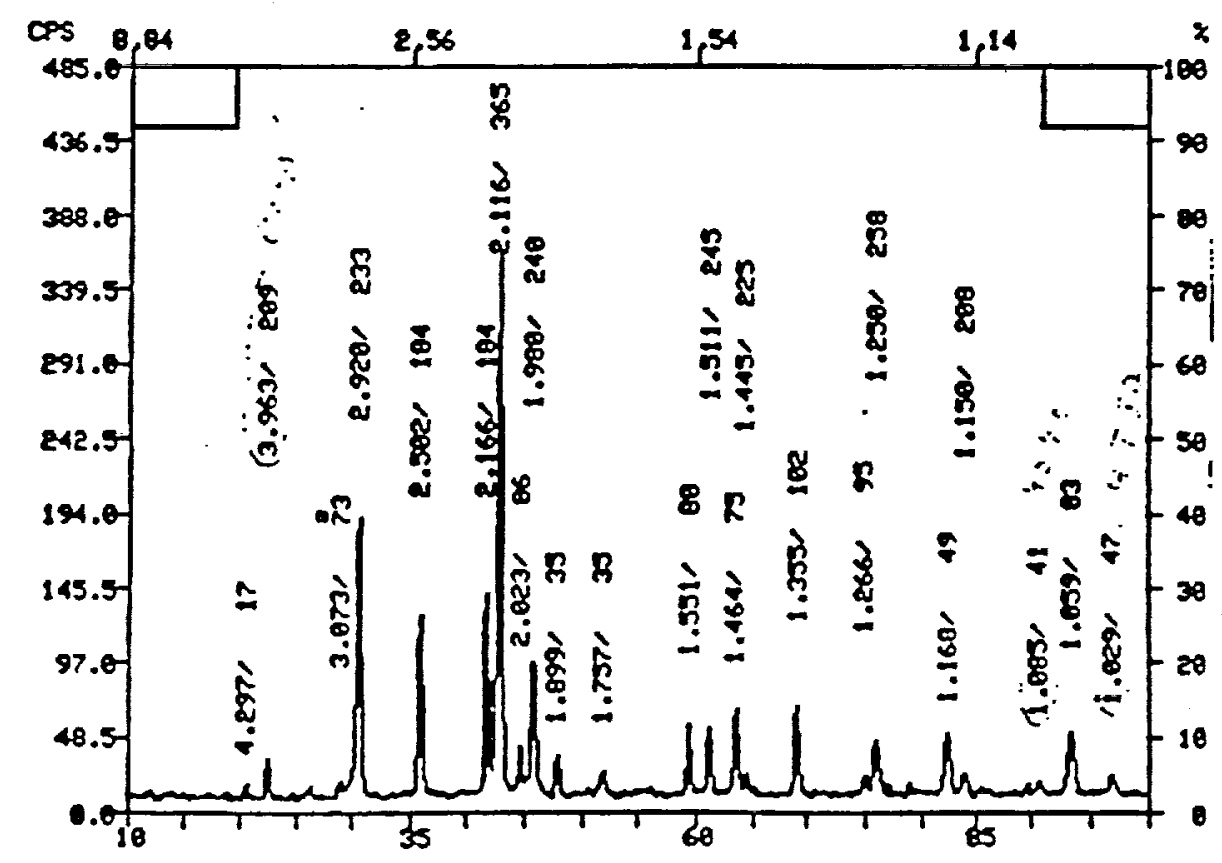

(b) Prepared by mechanical alloying and annealing.

Figure 2.-X-ray diffraction pattern of $\mathrm{LaNi}_{5}$ alloy. 

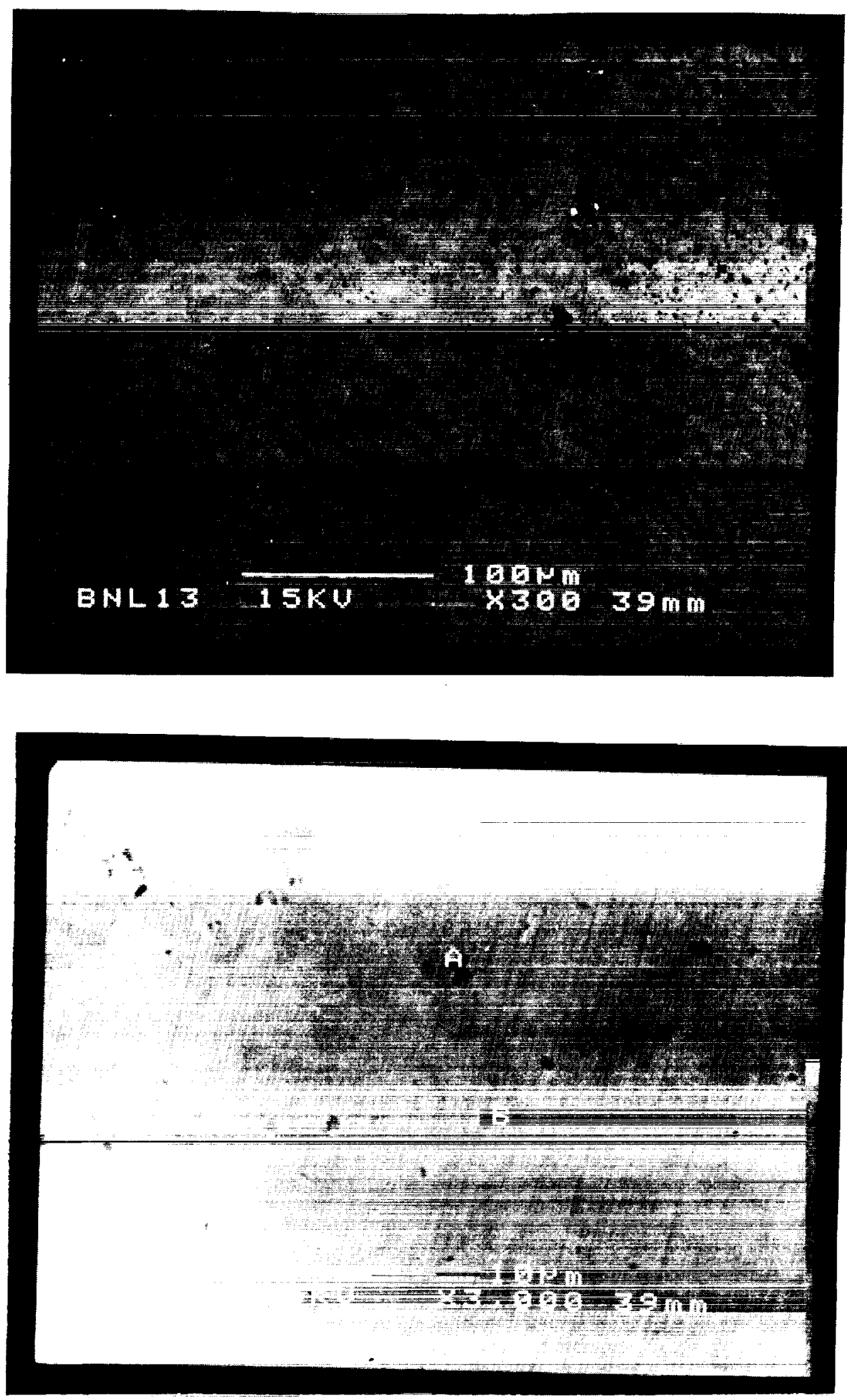

Figure 3.-Scanning electron micrographs for BNL-1 alloy, prepared by arc-melting. 

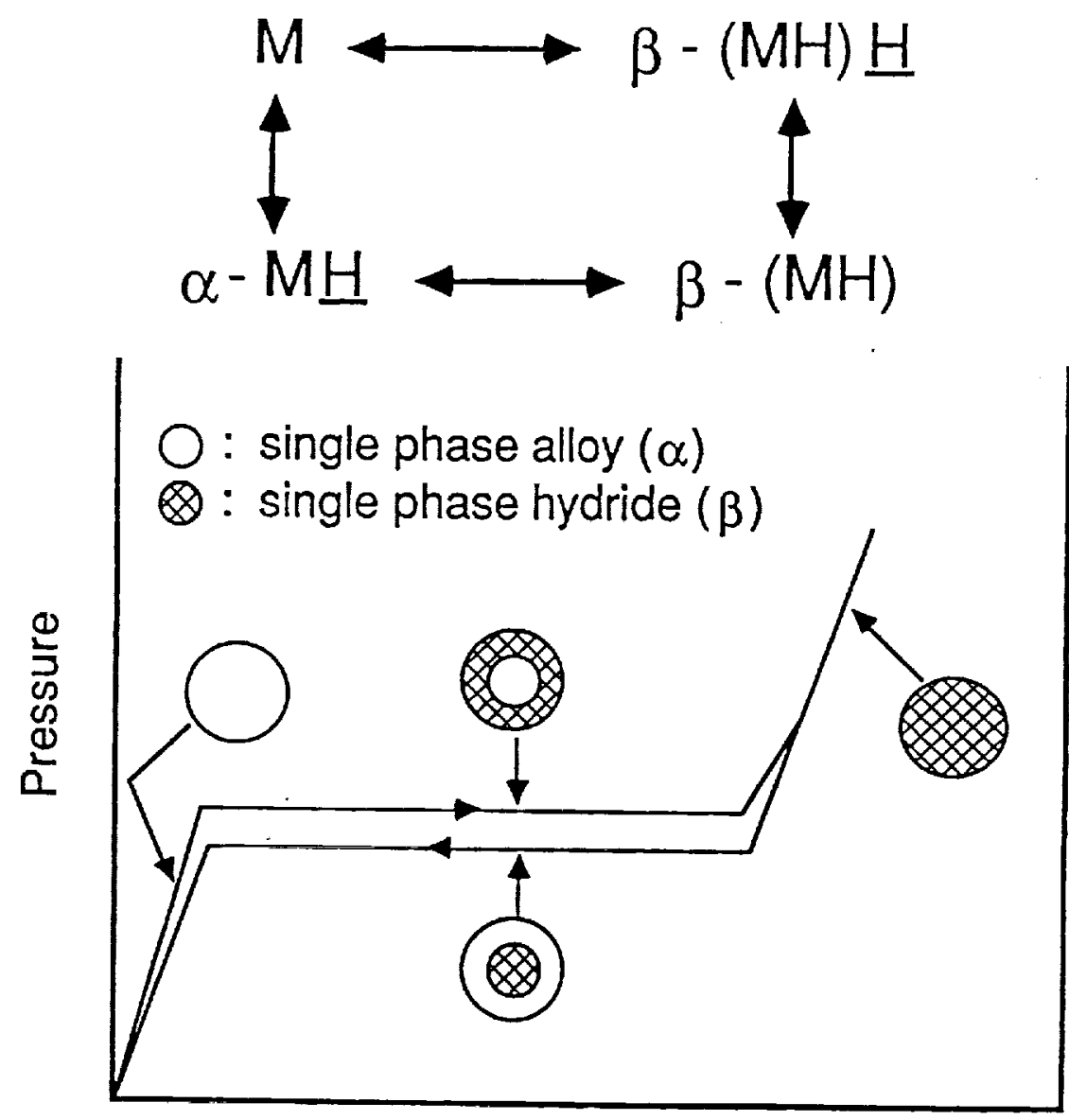

$[H]$ in Solids

Solid Solution : Sievert's Law

$$
P_{H_{2}}=f([H])
$$

Mixed Phase : van't Hoff Relation

$$
P_{H_{2}} \neq f([H])
$$

Figure 4.-Principles of hydrogen gas-phase absorption/desorption. 


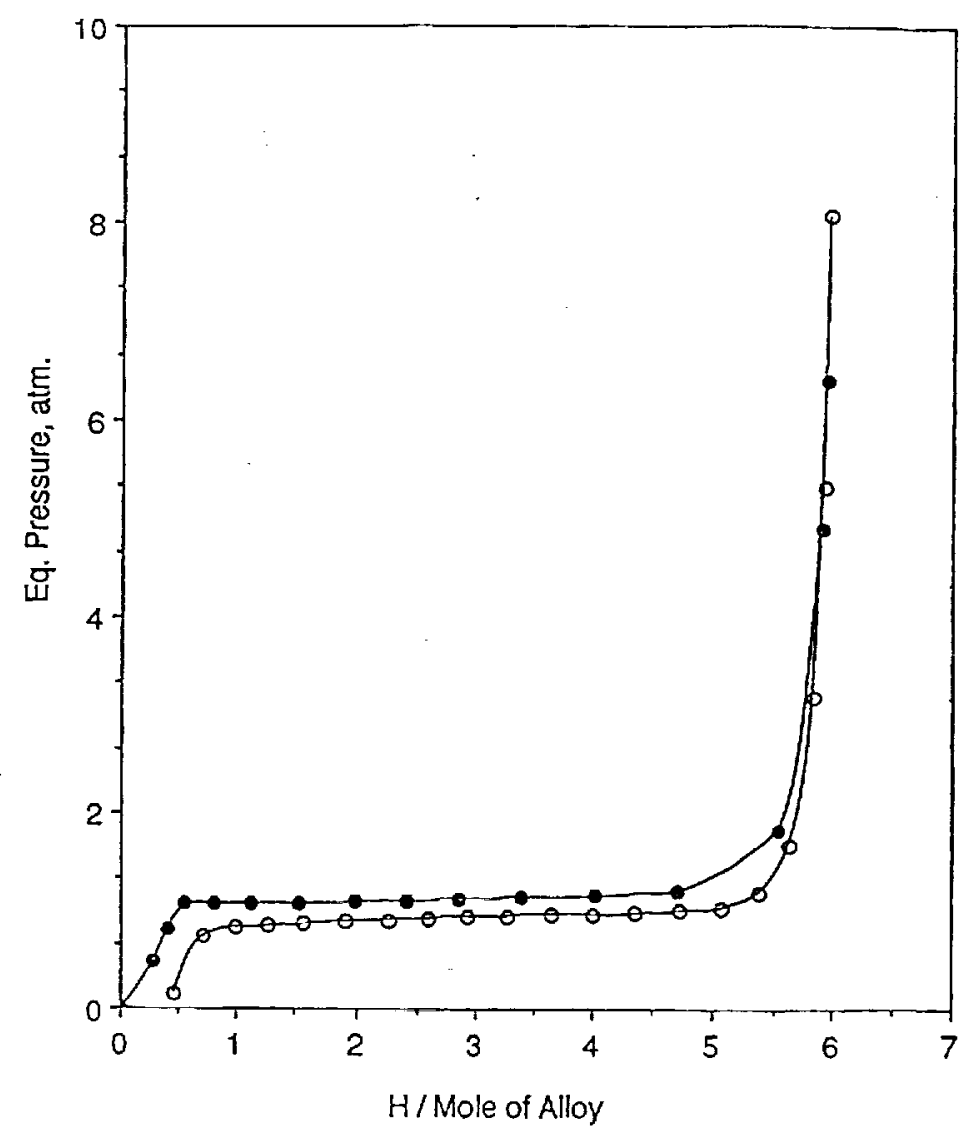

Figure 5.-Typical gas phase absorption/desorption isotherms showing minimal hysteresis effect. BNL-3; $25{ }^{\circ} \mathrm{C}$ open circle denotes desorption; solid circle denotes absorption.

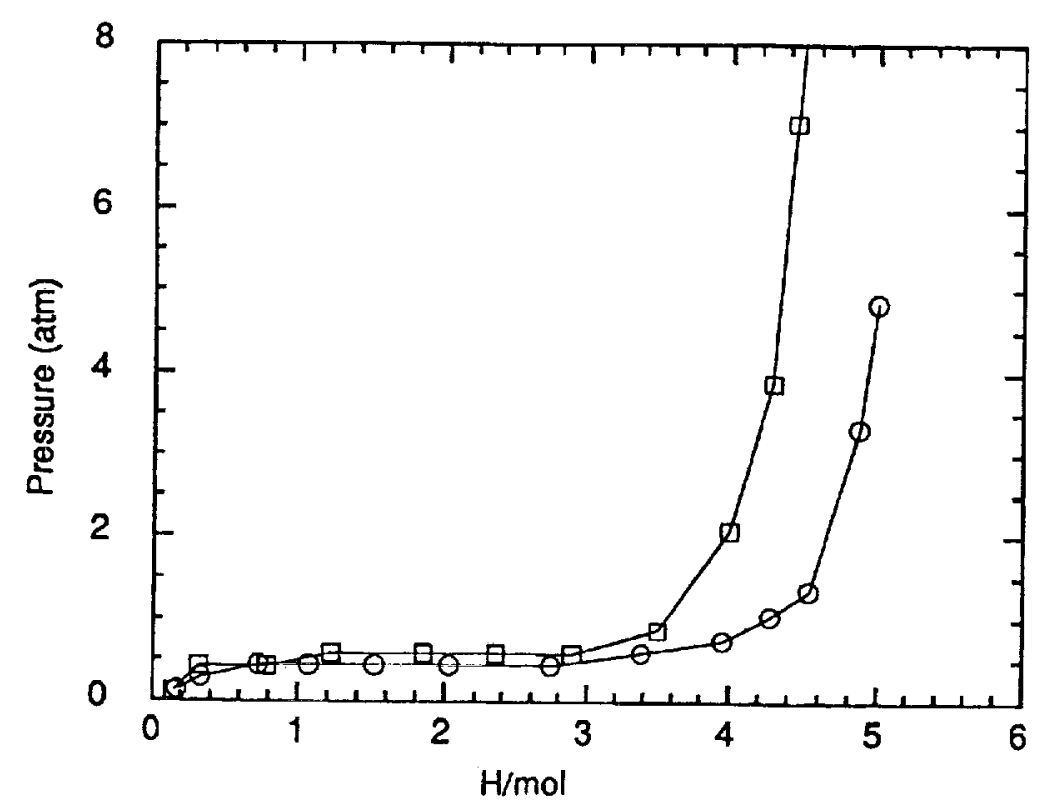

Figure 6.-Comparison of hydrogen absorption isotherms at $25^{\circ} \mathrm{C}$ for the $\mathrm{AB}_{5}$ type material. Open circle denotes arc-melted BNL-8. Square denotes mechanically alloyed and annealed LANL-2. 


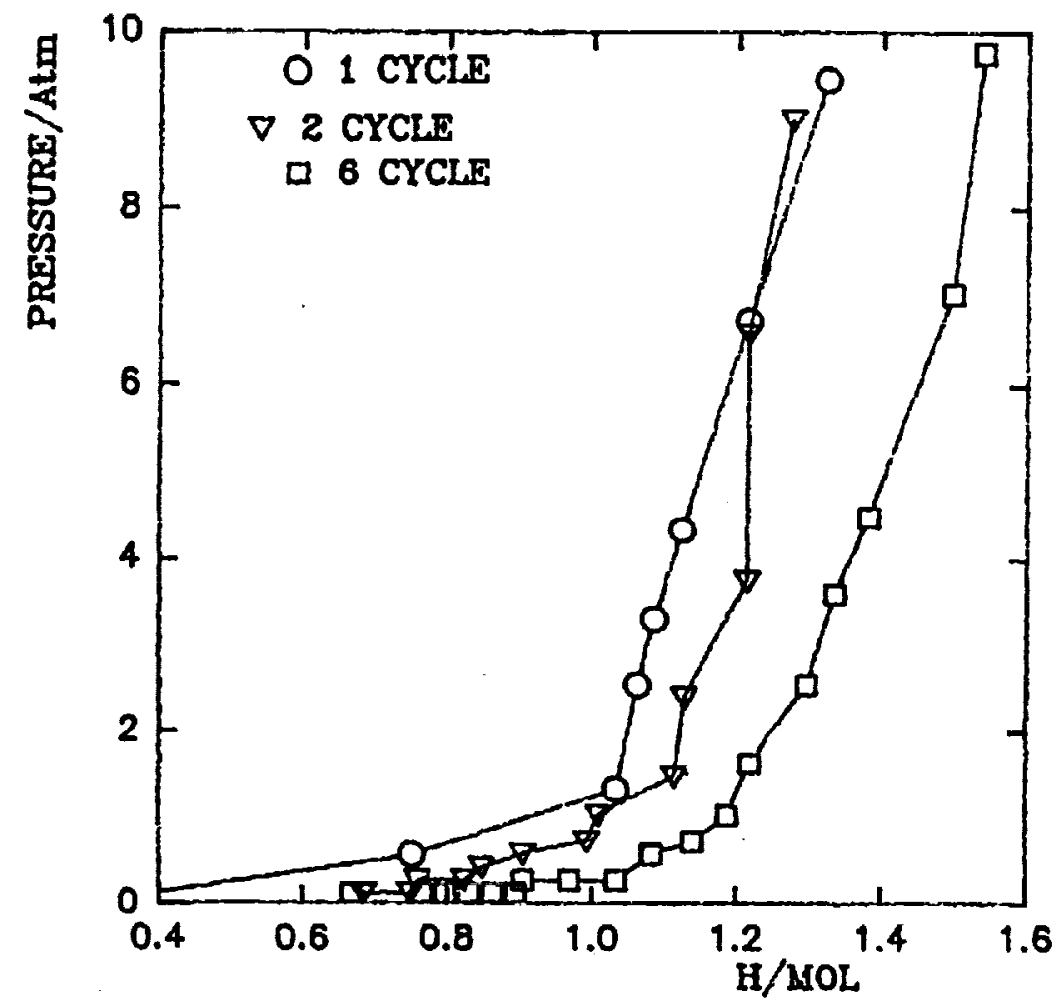

(a) Prepared over a $20 \mathrm{hr}$ period using tungsten carbide vial.

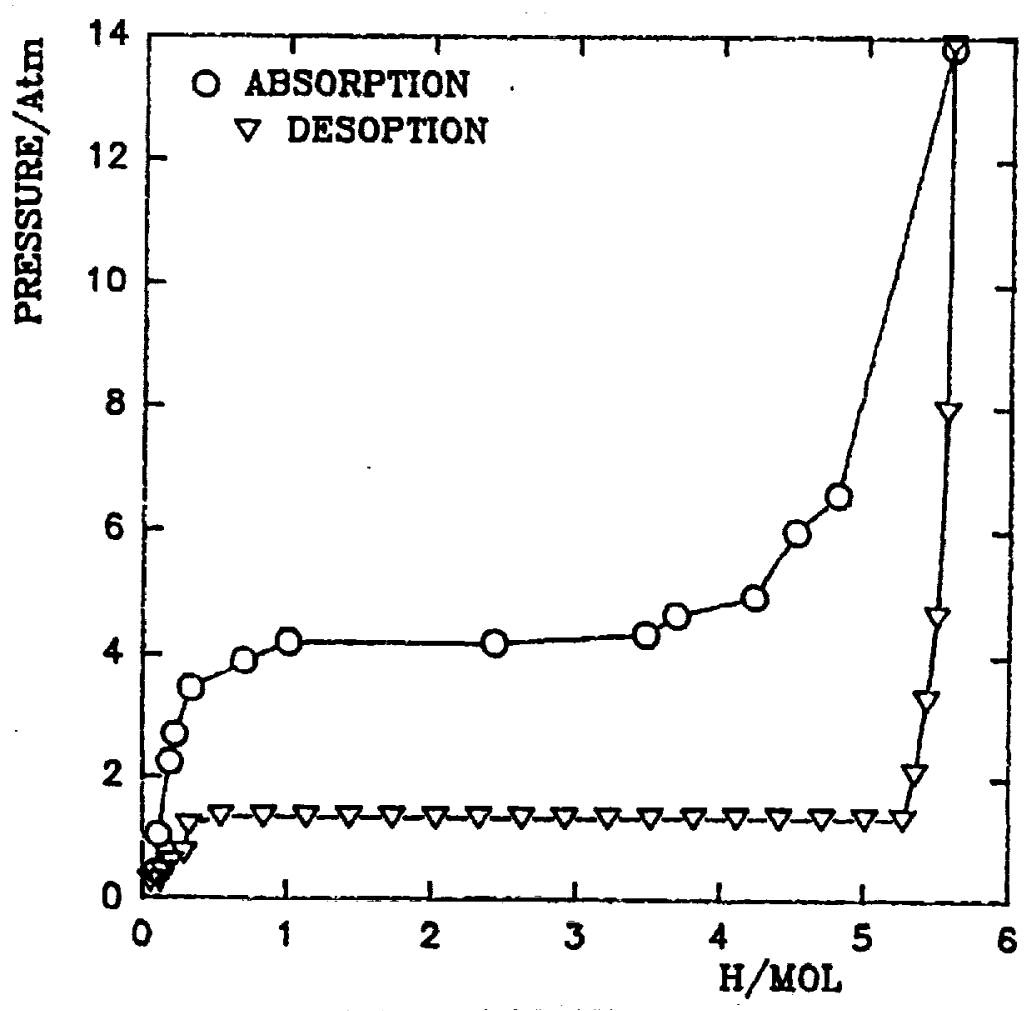

(b) Annealed at $700^{\circ} \mathrm{C}$ for $15 \mathrm{~min}$,

Figure 7.-Gas-phase absorption/desorption isotherms for $\mathrm{LaNi}_{5}$, prepared by mechanical alloying. 


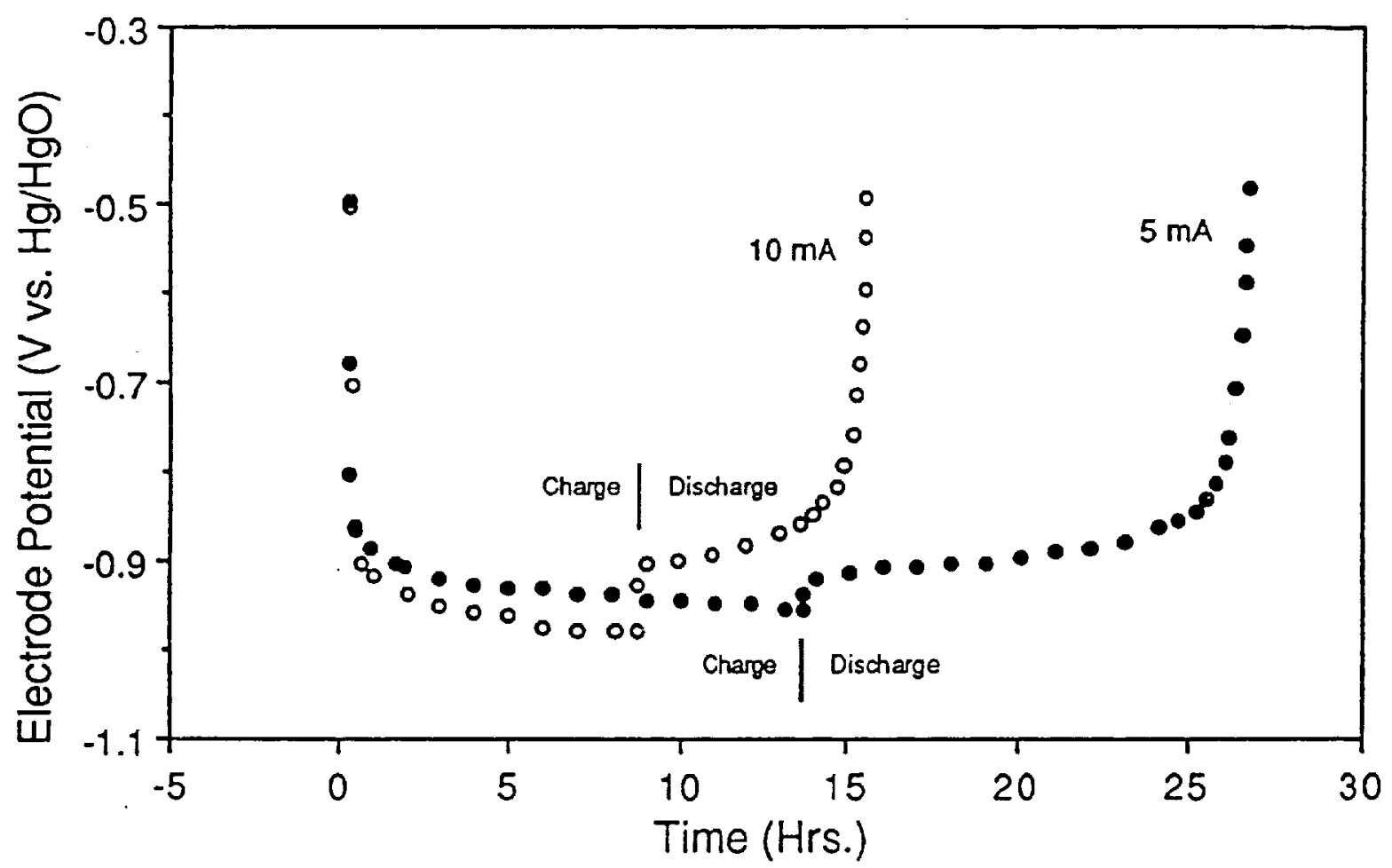

Figure 8.-Charge/discharge behavior of the electrode prepared with the BNL 3 material.

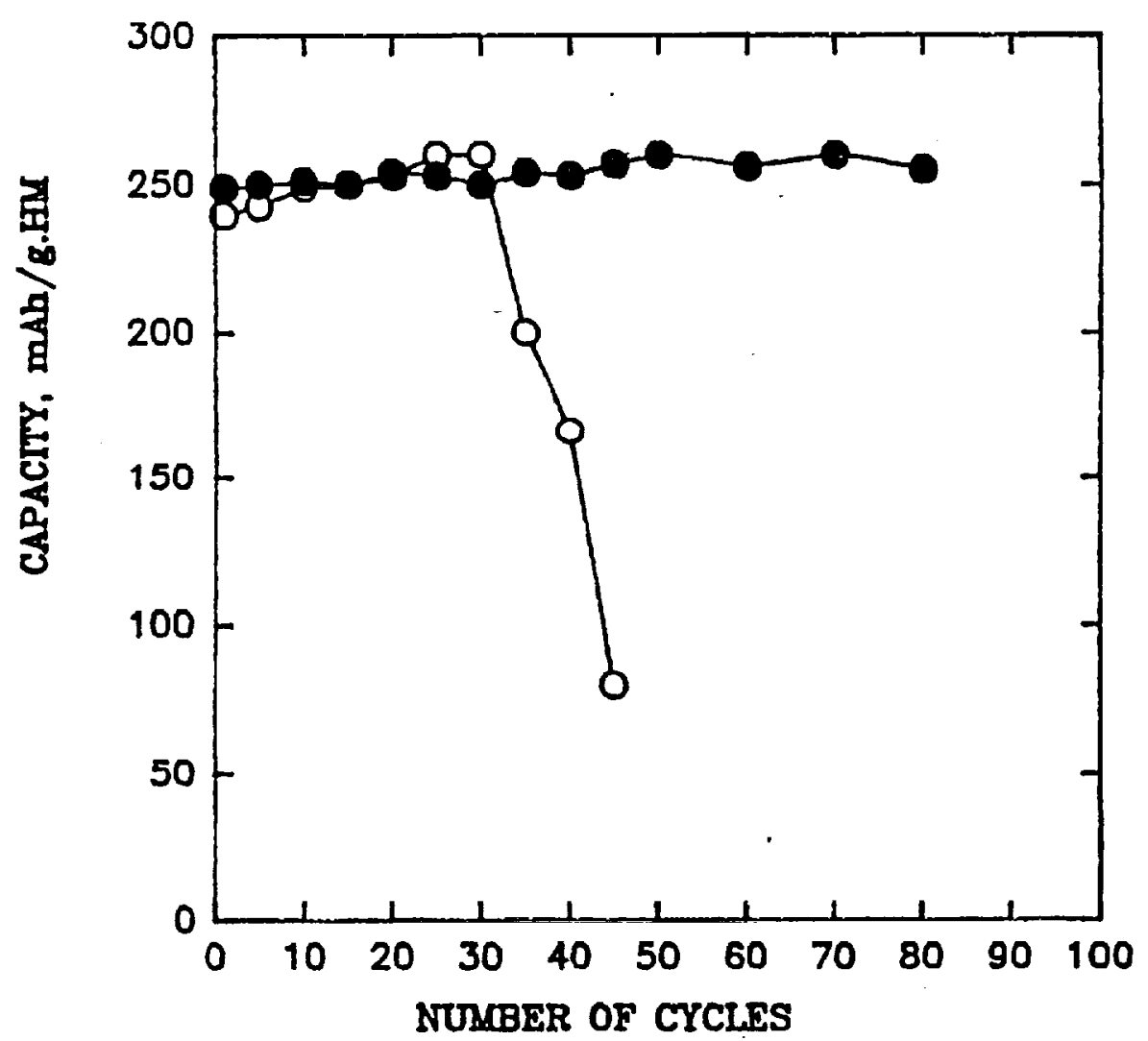

Figure 9.-Effect of additive to active material (LANL-3) on the cycle life of electrode. Open circle denotes LANL-3 + Teflonized acetylene black; solid circle denotes LANL-3 + Cu powder; $25^{\circ} \mathrm{C} ; 8 \mathrm{M} \mathrm{KOH}$. 


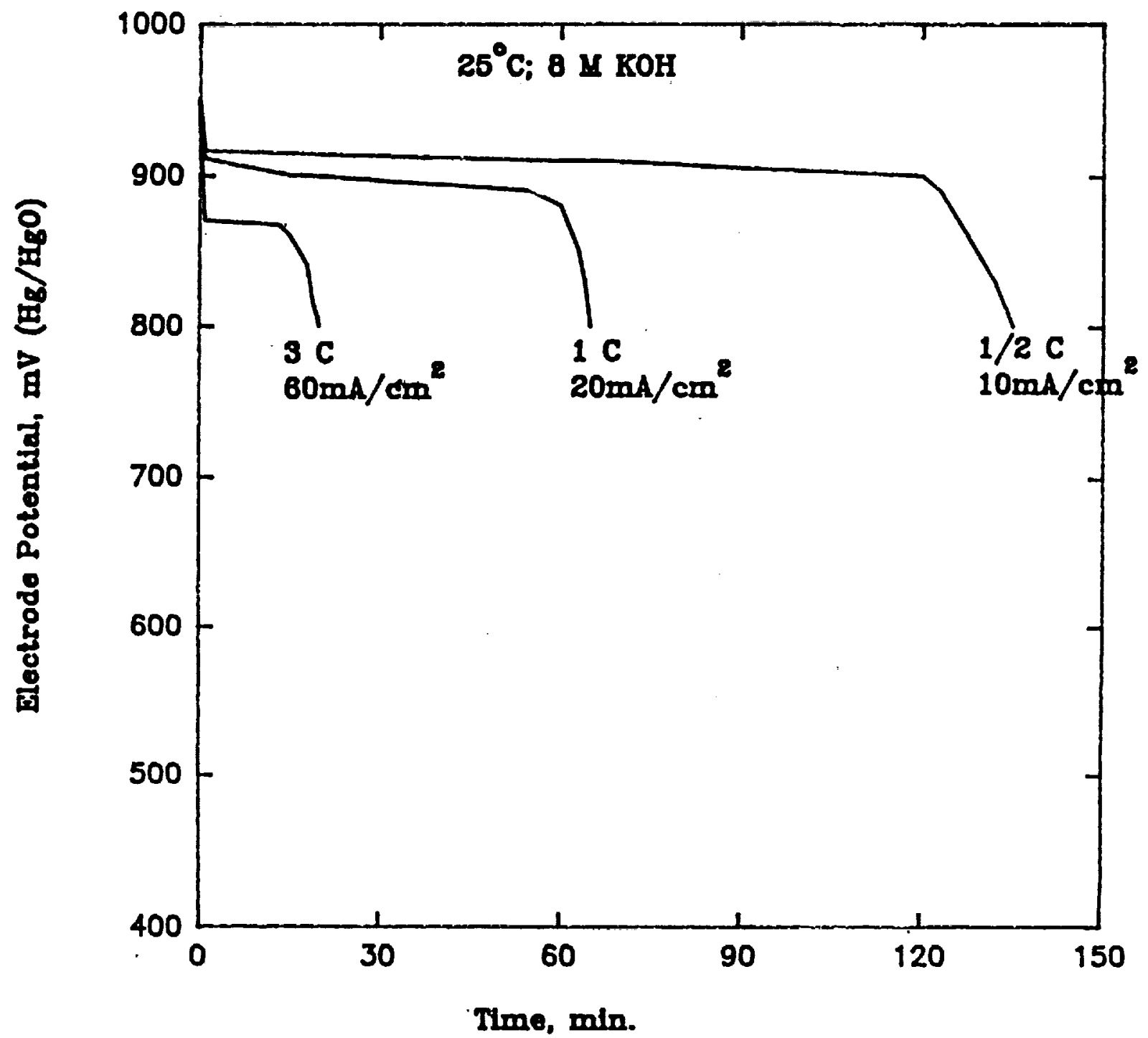

Figure 10.-Electrode potential versus time during discharge at different rates for electrodes with LANL-3 hydride material. Additive-Vulcan + 40\% PTFE. 


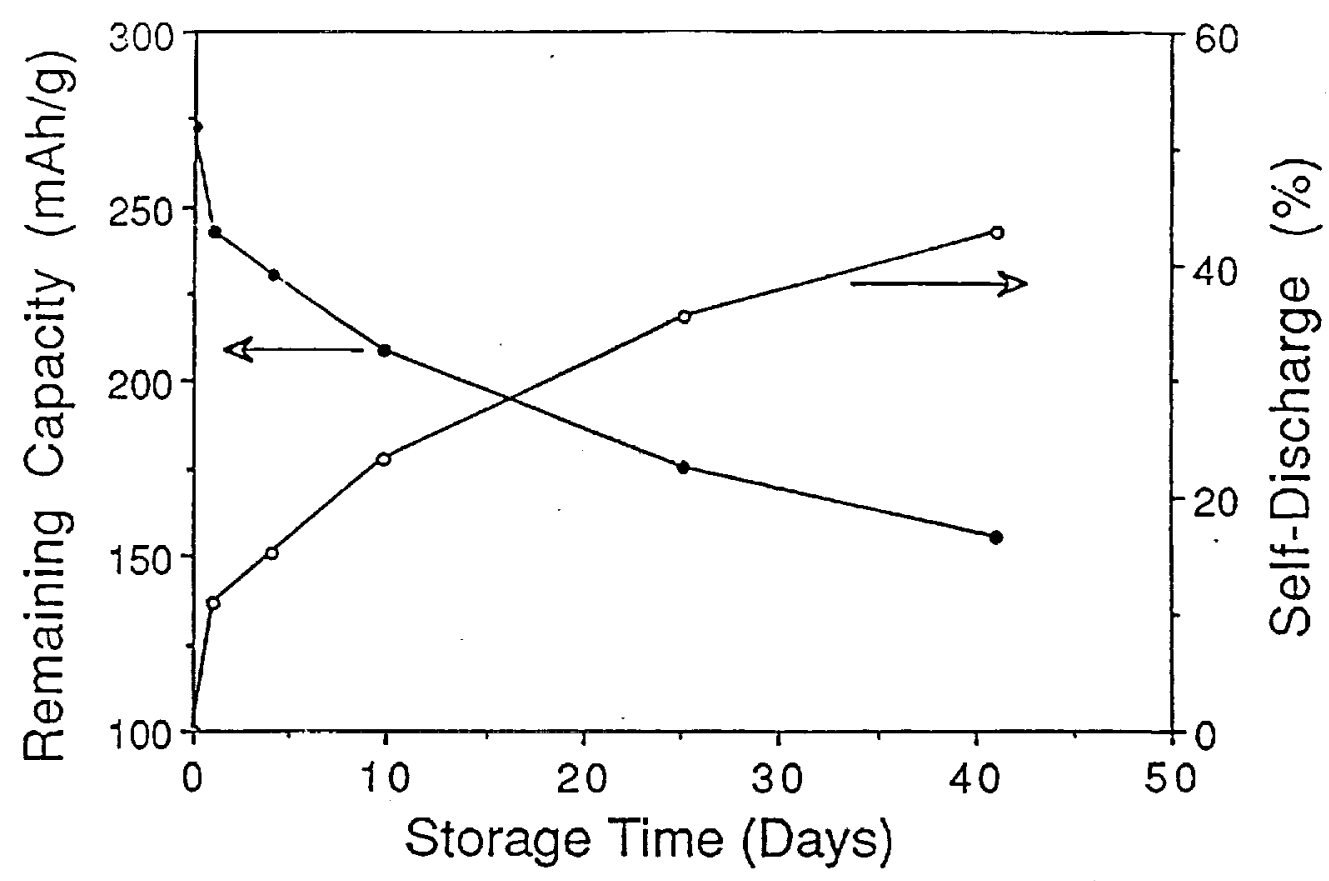

(a) Capacity retention.

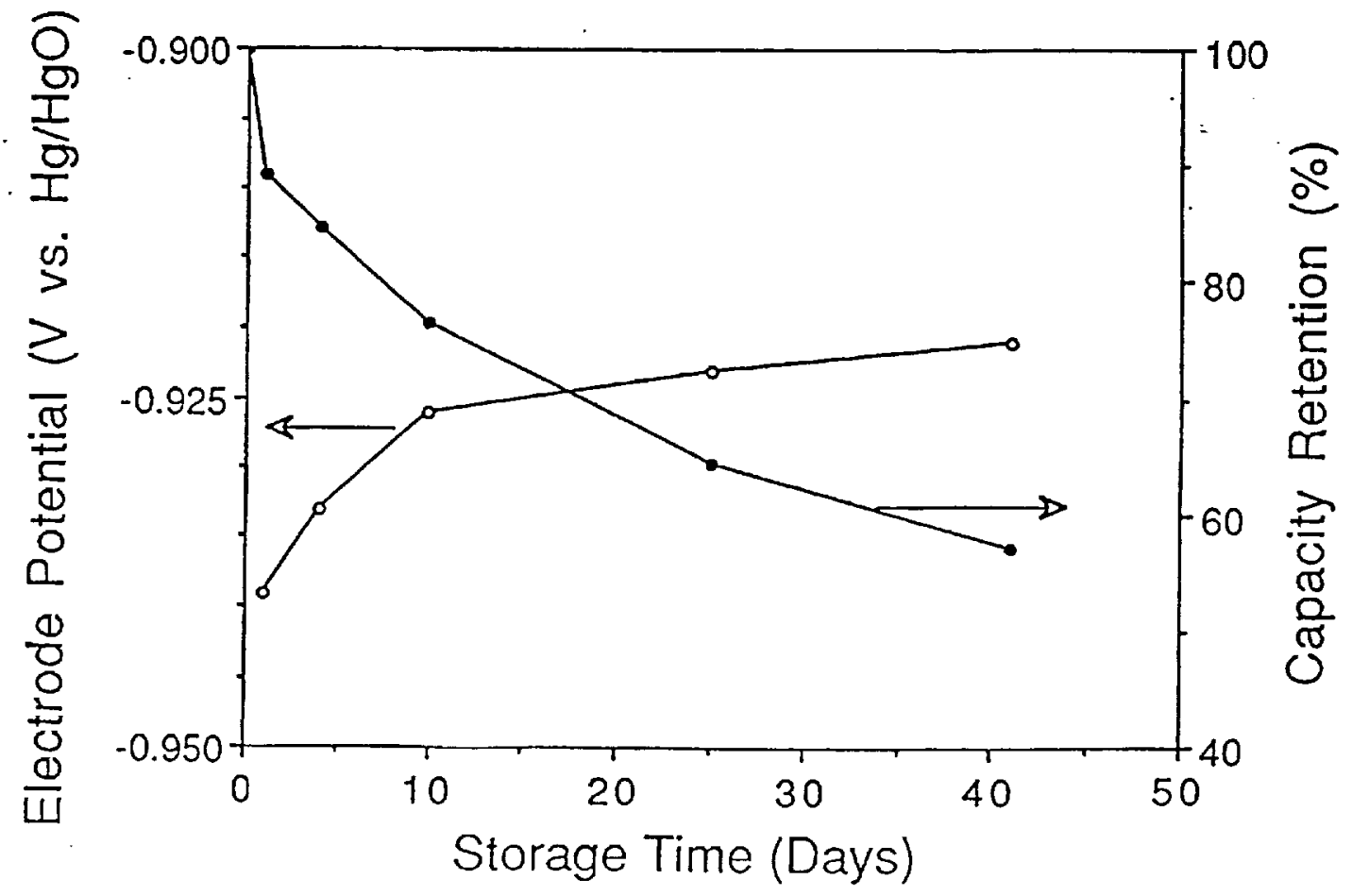

(b) Electrode potential and capacity retention.

Figure 11.-PRL-1 sample as a function of storage time. 


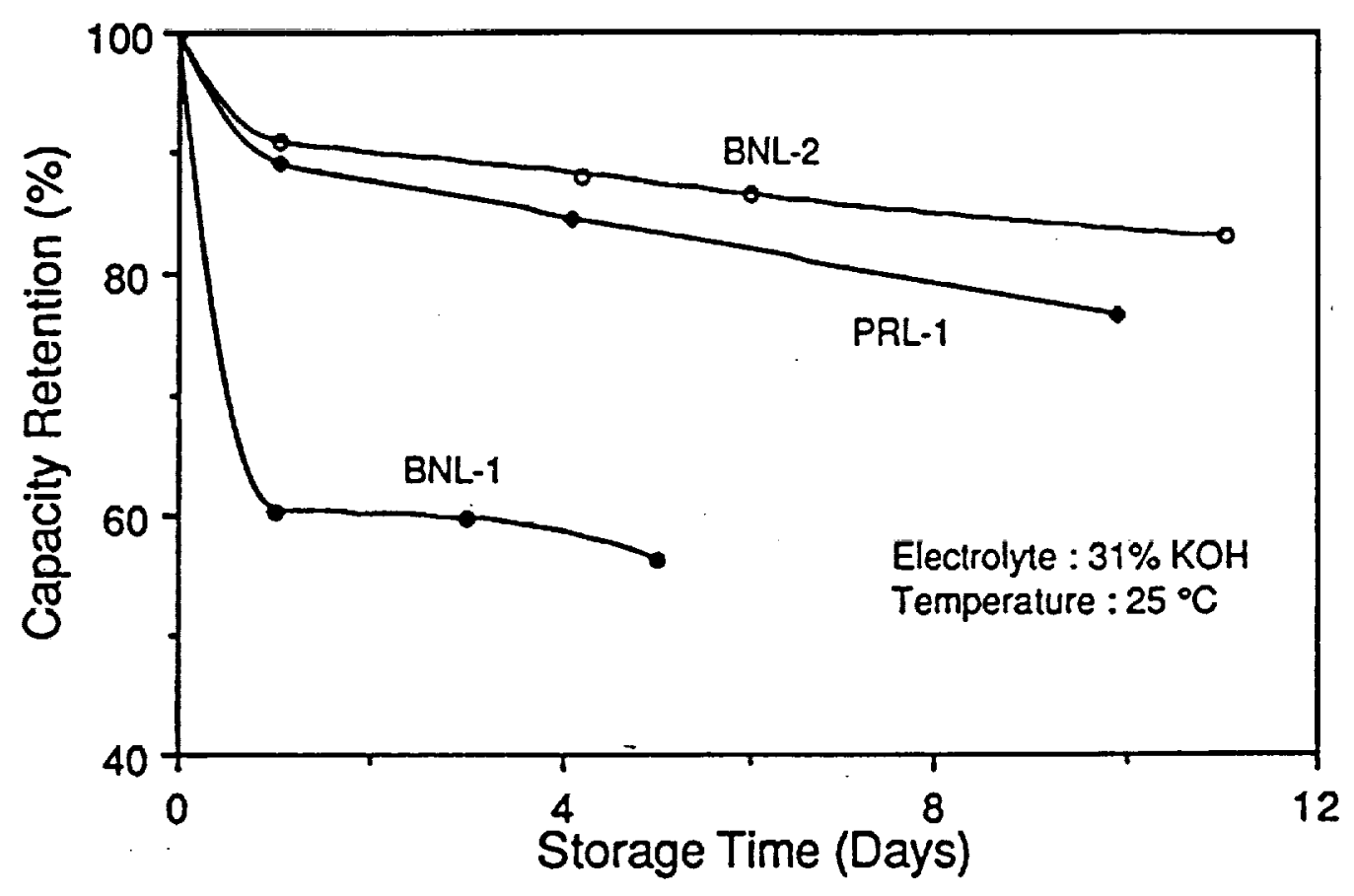

Figure 12.-Comparison of the capacity retention capabilities for the PRL-1, BNL-1, and BNL-2 alloy electrode samples. 